\title{
染料敏化太阳电池中染料的激发态超快动力学
}

刘忠范

北京大学化学与分子工程学院, 北京 100871

\section{Ultrafast Excited-State Dynamics of Organic Sensitizers in DSCs}

\section{LIU Zhongfan}

College of Chemistry and Molecular Engineering, Peking University, Beijing 100871, P. R. China.

Email: zfliu@pku.edu.cn

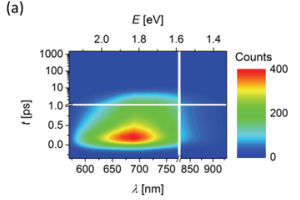

(b)
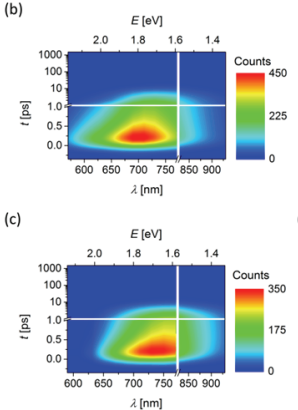
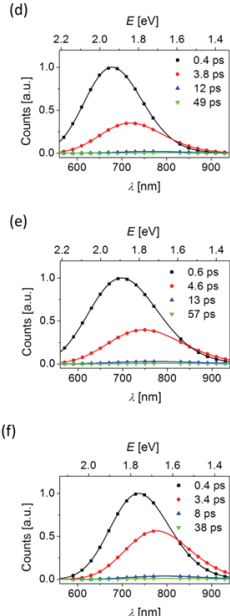
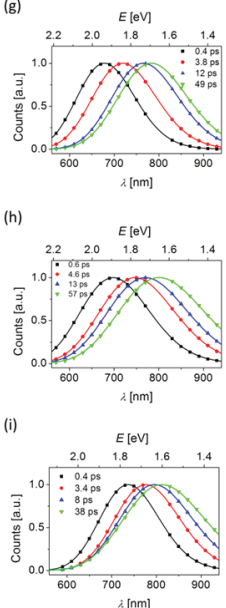
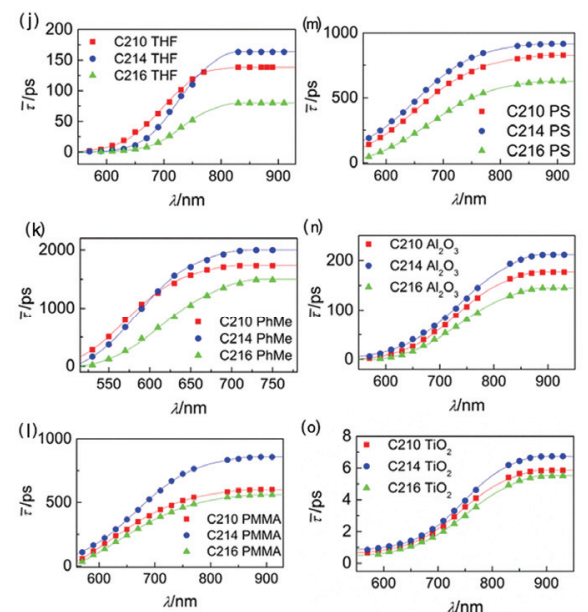

(a) C210、(b) $\mathrm{C214}$ 和 (c) $\mathrm{C} 216$ 吸附在 $\mathrm{TiO}_{2}$ 薄膜上的时间分辨发光光谱。(d) $\mathrm{C210}$ 、(e) $\mathrm{C214}$ 和(f) C216: 全局分析获得的 演化相关发光光谱(EAPL)。(g) C210、(h) C214 和(i) C216: 归一化的演化相关发光光谱(normalized EAPL)。染料 C210、 C214 和 C216 波长相关的平均时间常数：(j) THF 溶液、(k) PhMe 溶液、(l) PMMA 薄膜表面、(m) PS 薄膜表面、(n) 氧 化铝表面吸附、(o) 二氧化钜表面吸附

超快时间分辨光谱 (ultrfast time-resolved spectroscopy) 在飞秒甚至皮秒至纳秒时间尺度通 过光谱技术探究超快的物质运动和变化, 可用于 研究激发态、过渡态的的瞬时结构变化和能量变 化, 可以获得化学反应的实时物理图象。该技术诞 生于 1987 年, 并于 1999 年获得诺贝尔化学奖 ${ }^{1,2}$, 目前已广泛应用于分子激发态、光化学反应、光电 光伏材料中的能量转移和电荷转移、纳米材料瞬 态过程表征、生命科学等诸多领域。

染料敏化太能电池中, 二氧化钠/染料/电解质 界面光伏转换与电荷转移是其核心过程, 研究染
料分子吸收光后产生激发态的吸收和发射光谱的 超快动力学特征对优化材料设计、理解光伏转换 具有重要价值 ${ }^{3-10}$ 。

最近, 中国科学院长春应用化学研究所董献 堆课题组和天津理工大学张敏教授合作, 使用超 快时间分辨光谱研究了核心共轭基团分别为并呋 喃、并噻吩及并硒酚的三个有机染料 C210、C214 和 C216 的激发态及电荷转移动力学。通过在四氢 呋喃(THF)及甲苯(PhMe)溶液、聚甲基丙烯酸甲酯 (PMMA) 及聚苯乙烯聚合物 $(\mathrm{PS})$ 、离子液体电解质 为 Z952-CBSO 的氧化铝及二氧化钛薄膜等多种不 
同媒介中的激发态动力学对比研究, 发现伴随电 荷分离和注入过程, 非平衡激发态会发生分子内 分布驰豫, 表现为超快苂光上的动态斯托克斯位 移现象, 平衡激发态对电荷分离和注入过程有最 大贡献。该研究工作近期已在物理化学学报上在线 发表(doi: 10.3866/PKU.WHXB201709082) ${ }^{11}$ 。该工 作对研究激发态驰豫变化过程对染料分子设计、 理解染料敏化太阳电池机理、优化器件性能的影 响提供了帮助。

\section{References}

(1) Zewail, A. H. J. Phys. Chem. 1996, 100, 12701. doi: $10.1021 /$ jp960658s

(2) Wong, Y. X.; Chen, H. L. Ultrafast Spectroscopy-Principles and Techniques; Chemical Industry Press: Beijing, 2013. [翁羽翔，陈海 龙. 超快激光光谱原理与技术基础. 北京: 化学工业出版社, 2013.]

(3) Pelet, S.; Moser, J. E.; Grätzel, M. J. Phys. Chem. B 2000, 104, 1791. doi: $10.1021 /$ jp9934477

(4) Luo, L.; Lo, C.; Lin, C.; Chang, I.; Diau, E. J. Phys. Chem. B 2006,
110, 410. doi: 10.1021/jp055365q

(5) He, J., Benkö, G.; Korodi, F.; Polívka, T.; Lomoth, R.; Åkermark, B.; Sun, L.; Hagfeldt, A.; Sundström, V. J. Am. Chem. Soc. 2002, 124, 4922. doi: 10.1021/ja0178012

(6) Koops, S. E.; O’Regan, B. C.; Barnes, Pi. R. F.; Durrant, J. R. J. Am. Chem. Soc. 2009, 131, 4808. doi: 10.1021/ja8091278

(7) Benkö, G.; Kallioinen, J.; Korppi-Tommola, J. E. I.; Yartsey, A. P.; Sundström, V. J. Am. Chem. Soc. 2002, 124, 489. doi: $10.1021 / \mathrm{ja} 016561 \mathrm{n}$

(8) Bräm, O.; Cannizzo, A.; Chergui, M. Phys. Chem. Chem. Phys. 2012, 14, 7934. doi: $10.1039 / \mathrm{c} 2 \mathrm{cp} 40590 \mathrm{c}$

(9) Juozapavicius, M.; Kaucikas, M.; van Thor, J. J.; O’Regan, B. C. J. Phys. Chem. C 2013, 117, 116. doi: 10.1021/jp309732z

(10) Yang, L.; Li, Y.; Chen, S.; Zhang, J.; Zhang, M.; Wang, P. Acta Phys. -Chim. Sin. 2016, 32, 329. [杨林, 李阳, 陈淑, 张静, 张敏, 王鹏. 物理化学学报, 2016, 32, 329.] doi: 10.3866/PKU.WHXB201511031

(11) Liu, J.; Huo, J.; Zhang, M.; Dong, X. Acta Phys. -Chim. Sin. 2018, 34, 424. [刘娇, 霍继存, 张敏, 董献堆. 物理化学学 报, 2018, 34, 424.] doi: 10.3866/PKU.WHXB201709082 